\title{
Processo de desenvolvimento de software aplicado no gerenciamento de patrimônio
}

\author{
Tábata Fernandes Pereira
}

Fundação de Ensino e Pesquisa de Itajubá - FEPI

tabatafp@gmail.com

Rafael de Carvalho Miranda

Universidade Federal de Itajubá - UNIFEI

mirandaprod@yahoo.com.br

\begin{abstract}
RESUMO
A tecnologia da informação e seus inúmeros componentes são considerados fatores essenciais para a sobrevivência de qualquer empresa, trazendo grandes benefícios a seus usuários na otimização de tarefas diárias, na minimização de esforços e no melhor aproveitamento do tempo. Esse artigo tem como objetivo propor uma ferramenta computacional que armazene os bens patrimoniais de uma unidade acadêmica pertencente à Universidade Federal de Itajubá. A unidade possuía problemas decorrentes da gestão dos dados pertencentes a seu patrimônio, o que lhe ocasionava problemas recorrentes em auditorias realizadas pela União. A ferramenta computacional possibilitou aos usuários a realização de consultas ao patrimônio de forma ágil e mostrou como a execução de atividades diárias pode ser facilitada. Os resultados com o desenvolvimento do projeto e o uso da ferramenta serviram para identificar a aceitabilidade do software pelos usuários e os benefícios trazidos com a utilização de ferramentas de TI no meio organizacional.
\end{abstract}

Palavras-chave: Software, Gerenciamento de Patrimônio, Tecnologia da Informação.

\begin{abstract}
Information technology and its numerous components are considered a main factor for business survival in all sectors. As an essential building block, information technology can offer great benefits in daily task optimization, minimizing strains and enabling employees to make the best of their time. This article seeks to use a computational medium and software to replace papers and information stored in a disorganized and messy way with a solid, integrated computerized database. Using the software helped show the Federal University of Itajubá how the execution of common processes can be facilitated with the software's application. The results generated from the suggested project's development contributed to identify benefits of information technology tools in organizational environments.
\end{abstract}

Keywords: Software, Asset Management, Information Technology. 


\section{Introdução}

A evolução das tecnologias e os avanços ocorridos com os estudos para seu aprimoramento fizeram com que estas se tornassem cada vez mais democráticas, estando presente nas mais diversas classes e organizações. A essas tecnologias, que foram desenvolvidas ao longo do tempo, dá-se o nome de Tecnologia da Informação (TI), que envolvem várias outras formas de tecnologias e equipamentos computacionais, não se restringindo somente ao computador, como era entendido antigamente. As organizações no século XXI operam na economia digital, as quais incluem redes de comunicações (internet, intranets, extranets), computadores, softwares, entre outras ferramentas (TURBAN; RAINER; POTTER, 2005), estando presentes no cotidiano das pessoas e influenciando de forma significativa a sociedade.

Alguns autores acreditam que a TI seja um aglomerado de informações, tecnologias e equipamentos computacionais que, trabalhando juntos, possuem o objetivo de armazenar informações e gerenciá-las adequadamente, para que sirvam como apoio aos usuários, facilitando assim suas tarefas diárias. Dessa forma, as organizações tendem a investir em tecnologias como meio de competitividade e estratégia. A constante evolução dos negócios, mercados e economia acarretam uma turbulência acentuada e a cada dia o volume de dados cresce. Assim, a Tecnologia da Informação pode ser decisiva para o sucesso ou fracasso de uma empresa, contribuindo para que a organização seja ágil, flexível e forte (ALBERTIN, 2001).

O uso da TI nas empresas pode auxiliar no gerenciamento de seus dados e constituir-se em ferramenta de auxílio nas atividades, gerando um diferencial que, se bem utilizado, pode trazer benefícios e lucros à organização. Assim, devido a essa evolução da tecnologia da informação, as organizações necessitam de sistemas de informações computacionais, que, além de ajudarem a concluir com êxito seus negócios, contribuam para a criação de estratégias e para a definição de metas, com vistas a superar seus concorrentes (SILVA; GOMES; SILVA, 2007).

Para Silva, Gomes e Silva (2007), a concorrência e a competitividade no mundo empresarial globalizado estão cada vez mais acirradas, já que a procura por novos mercados é contínua. Qualquer diferencial, seja estratégico ou tecnológico, é de suma importância e pode ser decisivo para o melhor posicionamento da organização face à concorrência. Entre alguns diferenciais possíveis, um software empresarial que administra, gerencia, controla e fornece diversas informações é uma alternativa considerável.
Esse artigo apresenta o processo de desenvolvimento de software aplicado no gerenciamento de patrimônio dos bens do Instituto de Engenharia de Produção e Gestão (IEPG) da Universidade Federal de Itajubá (UNIFEI). Este trabalho visa solucionar problemas enfrentados pelo Instituto, propondo como objetivo final a implementação de um software que gerencie as informações e garanta a segurança e a confiabilidade dos dados.

Para cumprir com o objetivo estabelecido, esse trabalho encontra-se organizado em seis seções. A primeira, já apresentada, fez uma breve introdução ao artigo. A segunda apresenta a fundamentação teórica sobre os principais conceitos de patrimônio e tecnologia da informação. A terceira seção apresenta o método de pesquisa utilizado no desenvolvimento do trabalho. A quarta seção apresenta o objeto de estudo, o processo de desenvolvimento do projeto, a aplicação do trabalho e os problemas enfrentados. A quinta seção mostra os resultados da análise da aceitabilidade do software. E, por fim, a última seção traz as conclusões do trabalho.

\section{Fundamentação teórica}

\subsection{Patrimônio}

De acordo com Martins e Campos (2009) patrimônio pode ser conceituado como o conjunto de bens, valores, direitos e obrigações de uma pessoa, física ou jurídica, que possa ser avaliado monetariamente e que seja utilizado na realização de seus objetivos sociais. Ainda para esses autores, a esse conjunto de bens pode-se entender que, por transmitirem a ideia de que são capazes de gerar produtos e serviços e, portanto produzir riquezas, muitas vezes são considerados como sinônimos de recursos. Assim, um automóvel, considerado como um bem móvel pode ser ainda utilizado na prestação de um serviço com valor econômico e, como tal, é um recurso (MARTINS; CAMPOS, 2009).

Conforme o Manual de Administração Patrimonial (2010), patrimônio público é o conjunto de bens e direitos, tangíveis ou intangíveis, adquiridos, formados ou mantidos com recursos públicos integrantes do patrimônio de qualquer entidade pública, ou de uso comum, que seja portador ou represente um fluxo de benefícios futuros inerentes à prestação de serviços públicos.

São considerados como bens patrimoniais todos os equipamentos existentes em uma organização, seja de carácter público ou privado, englobando tudo que a organização possui: cadeiras, mesas, armários, computadores, terrenos, automóveis etc.. Enfim, são todos os bens que a empresa adquiriu e acumulou, ao longo de sua existência. 


\subsection{Gestão patrimonial da UNIFEI - IEPG}

Tanto instituições públicas como privadas devem realizar um inventário físico anual (auditorias) para justificar seus gastos. Esse inventário é uma declaração que contém uma relação de todos os bens patrimoniais existentes nas organizações. A Universidade Federal de Itajubá (UNIFEI), assim como as demais universidades, precisam realizar o levantamento de todos os bens ou materiais que estão sob sua responsabilidade (INSTRUÇÃO NORMATIVA n 205, 1988).

A UNIFEI possui seis unidades acadêmicas independentes, que são constituídas por Institutos administrados por diretores, os quais decidem a política adotada para a realização do inventário anual, visando cumprir a exigência legal disposta pela Instrução Normativa $n^{\circ}$ 205 (1988). O Instituto de Engenharia de Produção e Gestão (IEPG), local onde este trabalho foi desenvolvido, realiza anualmente o seu levantamento para a declaração de seus gastos.

A Instrução Normativa $n^{\circ} 205$ (1988) define material como sendo a designação para todos equipamentos, componentes, acessórios, veículos em geral, matérias-primas e outros itens empregados nas atividades das organizações públicas federais, independente de qualquer fator, bem como aqueles vindos de demolição ou desmontagem ou emprestados. O levantamento das informações visa comprovar a quantidade e o valor dos bens patrimoniais do acervo da instituição existente em 31 de dezembro de cada exercício, constituído do levantamento anterior e das variações patrimoniais ocorridas durante o exercício em curso (INSTRUÇÃO NORMATIVA n $\left.{ }^{\circ} 205,1988\right)$.

Os materiais em uso na instituição devem possuir identificação e números sequenciais de registro patrimonial. De acordo com a norma citada, o número de registro patrimonial deverá ser posto ao material mediante gravação, fixação de plaqueta ou de etiqueta apropriada. Os materiais que não possuírem tombo (número de registro) e se encontrarem em uso precisam ser identificados o mais rápido possível. Essa fixação de plaqueta possui uma sequência padronizada. O IEPG segue a instrução normativa e todos seus bens estão emplacados com a placa de identificação de patrimônio, conforme mostra a Figura 1.

Figura 1 - Placa de Patrimônio

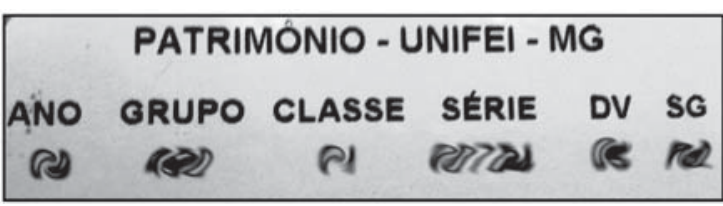

Fonte: Elaborado pelos autores
Após a distribuição do material, o usuário é responsável pelo bem que está sob sua guarda. Para a distribuição do material ou equipamento, a unidade requisitante deve-se estar com a devida carga e com o Termo de Responsabilidade, sendo obrigatória a assinatura do responsável que receberá a carga. Em caso de mudança de usuário, a transferência de responsabilidade obrigatoriamente deverá ser feita, devendo-se proceder à verificação física de cada material e assinatura de novo Termo de Responsabilidade (INSTRUÇÃO NORMATIVA $\left.n^{\circ} 205,1988\right)$.

O departamento de administração ou a unidade equivalente deve acompanhar a movimentação de material, colocar à disposição o material que for identificado como inativo nos almoxarifados ou os bens móveis distribuídos considerados ociosos (INSTRUÇÃO NORMATIVA n $\left.{ }^{\circ} 205,1988\right)$. De acordo com Laurindo et al. (2001), os procedimentos básicos para gestão patrimonial são: recebimento, etiquetagem, distribuição, emissão de termos de responsabilidade, guarda, recolhimento, redistribuição, baixas, alienação, inventários. Além disso, algumas organizações, em função dos tipos de bens móveis por elas utilizados, criam um desdobramento para esses procedimentos, criando até mesmo rotinas específicas.

Para o IEPG, o órgão responsável pela distribuição dos materiais nos Institutos é intitulado Prefeitura. Este órgão recebe o bem material em sua sede, faz a identificação dos bens com seu emplacamento e inclusão no sistema e, posteriormente, encaminha esse bem ao Instituto que o adquiriu, juntamente com o Termo de Responsabilidade que deve ser assinado pelo responsável.

\subsection{Tecnologia da informação}

A Tecnologia da Informação é um conjunto de ferramentas que gerencia as informações e serve como base para tomada de decisões. É também considerado um diferencial para as organizações. Rezende (2005), Rezende e Abreu (2003), Cruz (2000), Pacheco e Tait (2000) e Padoveze (2000), definem a Tecnologia da Informação como recursos tecnológicos e computacionais (computadores, softwares, redes de comunicação eletrônicas públicas e privadas, redes digital de serviços, tecnologia de telecomunicações, protocolos de transmissão de dados e outros serviços), que estão disponíveis a fim de melhorar a gestão da informação nas organizações.

Nesse contexto, a competitividade tem forçado as organizações a buscarem e implantarem novos modelos de gestão que as auxiliem na conquista de novos mercados consumidores e, ainda, a permanência neles. A tecnologia da informação é um recurso que, estando em sintonia com as necessidades e objetivos dos usuários, 
possibilita maior eficiência e eficácia no relacionamento interno e externo das organizações, evidenciando assim a agilidade e a qualidade no processo da tomada de decisão (TEIXEIRA; MENDONÇA; SOUZA, 2001). A TI é vista como uma das maiores e mais poderosas influências no planejamento das organizações, pois seu uso permite às organizações oferecerem aos clientes novas formas de serviços e serve como principal ferramenta para a gestão das informações.

A cada dia há um enorme aumento dos dados nas empresas, o que aumenta a complexidade das situações enfrentadas pelos gestores. Maximiano (2009) acredita que quanto maior o número de problemas e variáveis mais complexa é a situação. E ainda sugere que a ferramenta necessária para lidar com a complexidade é o enfoque sistêmico. Ainda o autor diz que o ponto de partida do enfoque sistêmico é a ideia de sistema, que ajuda a entender e dar soluções complexas para problemas complexos. Nesse contexto, as organizações têm buscado utilizar os sistemas para tentar resolver seus problemas.

De acordo com Turban, Mclean e Wetherbe (2002), o sistema de informação inclui: inputs (dados) e outputs (relatórios). Ele processa os inputs e produz outputs, que são enviados para o usuário e para outros sistemas. Pode conter também o mecanismo de feedback, que ocorre quando a saída de um sistema a ele retorna. Como qualquer outro sistema, o sistema de informação opera dentro de um ambiente necessariamente computadorizado.

Figura 2 - Visão esquemática de um Sistema de Informação

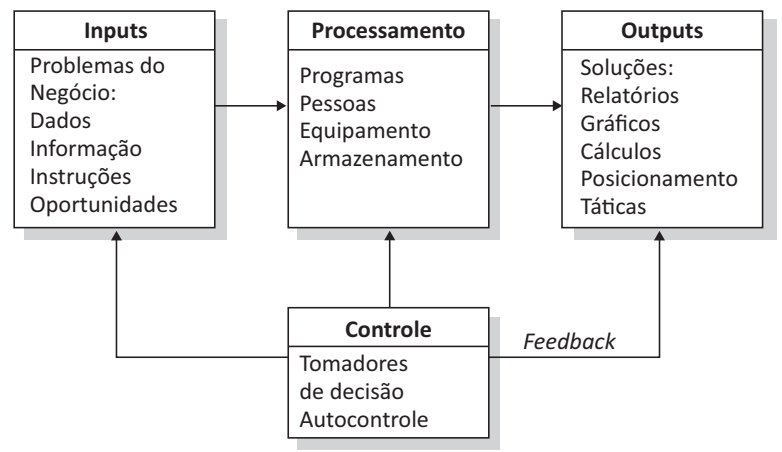

Fonte: TURBAN; MCLEAN; WETHERBE (2002)

Para Maximiano (2009), um sistema é um todo complexo ou organizado, um conjunto de partes ou elementos que formam um todo unitário e complexo. Dessa forma, empresas têm feito uso de softwares, que são sistemas computacionais, para tentar processar suas informações de entrada e obter dados de saídas, os quais possam servir de apoio nas tomadas de decisão. Porém, há um impasse na utilização de softwares para o gerenciamento de dados. Muitas empresas mantêm grandes softwares, que não sendo gerenciados, acabam se tornando ferramentas computacionais desatualizadas que não fornecem informações condizentes com a realidade.

Maximiano (2009) define a organização como um sistema composto de elementos ou componentes interdependentes. Dessa forma, todo sistema está integrado dentro de um ambiente formado por outros sistemas que se organizam em sistemas cada vez maiores. O gestor da empresa deve perceber que a organização é um todo que está dividido em partes. Assim, as informações contidas nesse todo devem ser gerenciadas adequadamente para que os subsistemas, as partes, possam fazer uso dos dados e trazer assim resultados previstos para a organização.

A informação é o bem mais valioso para as organizações e as decisões devem ser tomadas com base nessas informações. Para que isso seja possível, deve-se saber gerenciar as informações que a empresa possui. A gestão da informação é um fator imprescindível para a execução de um sistema de informação, mas não somente isso: é onde se pode repensar para que os objetivos organizacionais possam ser atingidos com eficiência e eficácia. A gestão do fluxo de informações passa a ter caráter estratégico na obtenção de vantagens competitivas, objetivo final de qualquer empresa. A melhoria da eficácia da utilização da informação passa a ser preocupação de todos os colaboradores e não somente da alta gerência ou do pessoal da informática (MARTINS; CAMPOS, 2009).

Para obter uma boa gestão da informação é necessário entender a importância que a informação significa para a organização. Raros profissionais se sentem seguros tomando ou justificando uma decisão empresarial não baseada em informações sólidas. As organizações devem ser capazes de obter, organizar, analisar e interpretar os dados para sobreviverem nos mercados globais supercompetitivos (TURBAN; RAINER; POTTER, 2005). Martins e Campos (2009) acreditam que as empresas procuram constantemente novas formas de se autoadministrarem, pois sabem que aí está um dos caminhos para conseguirem vantagens competitivas.

\section{Metodologia de pesquisa}

O trabalho desenvolvido segue o método de pesquisa RUP (Rational Unified Process), que oferece uma abordagem baseada em disciplinas para atribuir tarefas e responsabilidades dentro de uma organização de desenvolvimento. Sua meta é garantir a produção de software de alta qualidade que atenda às necessidades dos usuários dentro de um cronograma e de um orçamento previsível. RUP é um modelo constituído por quatro fases no processo de desenvolvimento de sistemas (SOMMERVILLE, 2007). O processo RUP é melhor apresentado conforme a Figura 3. 
Figura 3 - Metodologia Rational Unified Process

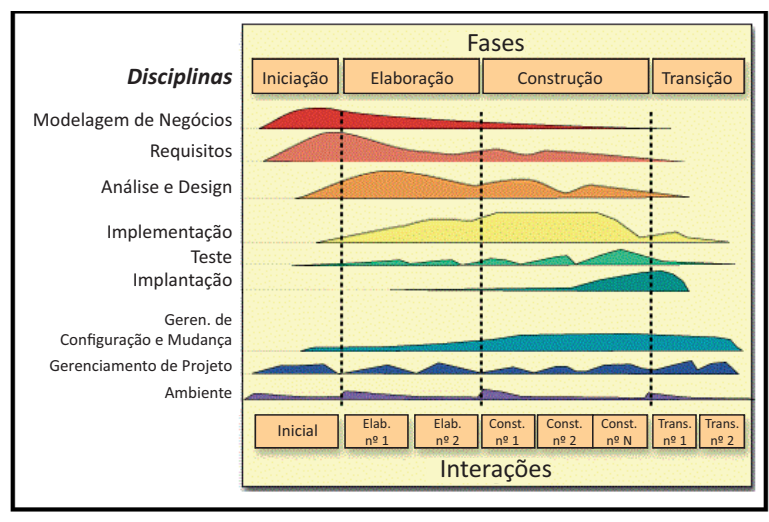

Fonte: SOMMERVILLE (2007)

Quaisquer que sejam as intenções e objetivos, novos sistemas constituem um produto de um processo de resolução de um problema organizacional. Um novo sistema de informação é montado como uma solução para algum tipo de problema ou conjunto de problemas que a organização detectou e está enfrentando. O problema pode surgir da percepção, por parte de gerentes e funcionários, de que o desempenho da organização não está sendo tão bom quanto o esperado, ou pode resultar da constatação de que a organização deveria tirar proveito de novas oportunidades para operar com maior sucesso (LAUDON; LAUDON, 2004).

Ainda segundo Laudon e Laudon (2004), para grandes empresas esse tipo de constatação, seja em pequenos ou grandes detalhes, podem ter um grande impacto no lucro, pois por estarem sendo executados de maneira não eficaz, traz a redução do mesmo. A Figura 4 mostra como deve se proceder no desenvolvimento de sistemas. Em seguida são apresentadas as quatro fases da metodologia RUP.

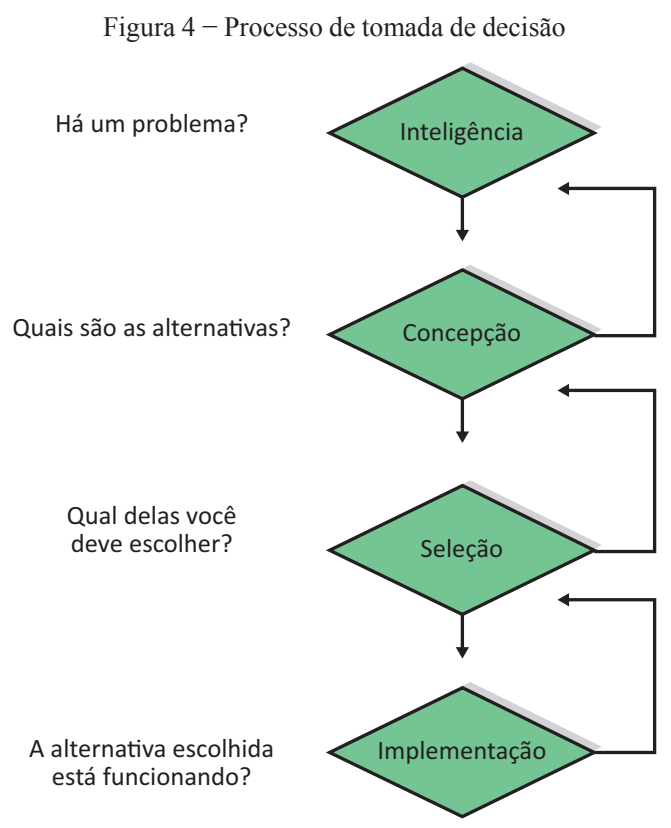

Fonte: LAUDON; LAUDON (2004)

\subsection{Concepção}

Laudon e Laudon (2004) acreditam que na fase da concepção é analisado o problema que a organização enfrenta e é iniciada a elaboração da solução com um sistema de informação ou outra ferramenta computacional. Consiste em definir o problema, identificar suas causas, especificar a solução e identificar os requisitos da informação que devem ser atendidos por uma solução de sistema.

Para Piske (2003), nessa etapa é realizada a concepção inicial do sistema, sendo organizadas discussões sobre o problema, a definição do escopo do projeto, estimativas de recursos e ferramentas necessárias para a execução do projeto etc. Com o intuito de obter um resultado satisfatório para ambas as partes é necessário que a fase de concepção seja bem definida e documentada para a continuidade do desenvolvimento do projeto.

\subsection{Elaboração}

Segundo Piske (2003), o propósito dessa fase é analisar o domínio do problema, desenvolver o plano de projeto, estabelecer a fundação arquitetural e eliminar os elementos de alto risco. Os elementos de risco a serem analisados, nessa fase, são os riscos de requerimentos tecnológicos (referentes à capacidade das ferramentas disponíveis), de habilidades (dos integrantes do projeto) e políticos.

Ainda Piske (2003) ressalta que essa é a fase mais crítica de todas, pois ao final desta, a engenharia é considerada completa e os custos para modificação do sistema aumentam à medida que o projeto avança. Do ponto de vista administrativo, é ao final dessa fase que um projeto deixa de ser uma operação de baixo risco e baixo custo para se tornar uma operação de alto risco e alto custo.

\subsection{Construção}

De acordo com Sommerville (2007), a fase de construção está essencialmente relacionada ao projeto, programação e testes de sistema. As partes do sistema são desenvolvidas paralelamente e integradas durante essa fase. Para Piske (2003), a fase da construção é constituída pelo desenvolvimento de telas, lógicas, relações, banco de dados e testes, utilizando alguma notação definida pela UML. É a fase em que o software é efetivamente programado através de códigos fontes.

Larman (2005) define UML como uma Linguagem de Modelagem Unificada visual, usada para especificar, construir e documentar os artefatos dos sistemas. A palavra visual é um ponto chave, pois a UML é a notação diagramática padrão para desenhar ou apresentar 
figuras relacionadas ao software. Neste trabalho, foi utilizada a linguagem UML para a construção da lógica da ferramenta computacional.

\subsection{Transição}

Segundo Laudon e Laudon (2004), na fase de transição devem ser feitos testes exaustivos e minuciosos para se assegurar que o sistema está produzindo resultados sólidos e satisfatórios. Para Sommerville (2007), a fase de transição é a fase final do RUP e está relacionada à transferência do sistema da comunidade de desenvolvimento para a comunidade dos usuários e à entrada do sistema em funcionamento no ambiente real. De acordo com Martins (2010), o objetivo desse processo é disponibilizar o sistema para os usuários, incluindo:

- Testes do sistema no ambiente de produção;

- Empacotamento de software para distribuição;

- Distribuição do software;

- Instalação do software;

- Treinamento dos usuários e equipe comercial;

- Migração de dados para novo sistema.

\section{Processo de desenvolvimento do software}

\subsection{Apresentação do objeto de estudo}

O desenvolvimento deste trabalho envolve o gerenciamento e controle dos bens patrimoniais do Instituto de Engenharia de Produção e Gestão (IEPG) da UNIFEI. Esses bens são compostos por materiais, tais como: cadeiras, mesas, equipamentos de informática (computadores, switches, roteadores), armários, projetores, entre outros. Ou seja, pelos bens ativos do Instituto.

Ao início deste trabalho, as informações referentes aos bens patrimoniais do IEPG se encontravam armazenadas em arquivos desagrupados. Cada arquivo continha informações referentes a uma sala e, sendo assim, o IEPG possuía aproximadamente 50 planilhas com informações duplicadas e que não possuíam um padrão de organização. Os arquivos eram nomeados com os nomes dos devidos responsáveis, sem nenhuma sistematização, como por exemplo, organizados alfabeticamente. Essa forma como eram armazenados os dados contribuía para a duplicidade de informações. Um mesmo bem poderia constar em várias planilhas, tornando difícil sua consulta, localização e atualização de seu status. Dessa forma, tornou-se comum a grande maioria dos arquivos conduzirem a informações erradas sobre os bens do Instituto.

Esse problema era enfrentado pelos funcionários do IEPG há muito tempo. A necessidade de encontrar algum bem ou material se tornava cada vez mais difícil à medida que o volume de informações nas planilhas aumentava. Para a realização anual das auditorias no Instituto, alguns funcionários do IEPG eram designados e ficavam responsáveis pela auditoria, porém estes encontravam grandes dificuldades devido à falta de organização e à forma de armazenamento destes dados. A Figura 5 apresenta um exemplo da forma como eram armazenados os dados referentes aos bens do Instituto.

\subsection{Fases de desenvolvimento}

Para o desenvolvimento do software foi necessário conhecer conceitos de Engenharia de Software. É uma disciplina da engenharia relacionada com todos os

Figura 5 - Exemplo de armazenamento de dados do IEPG

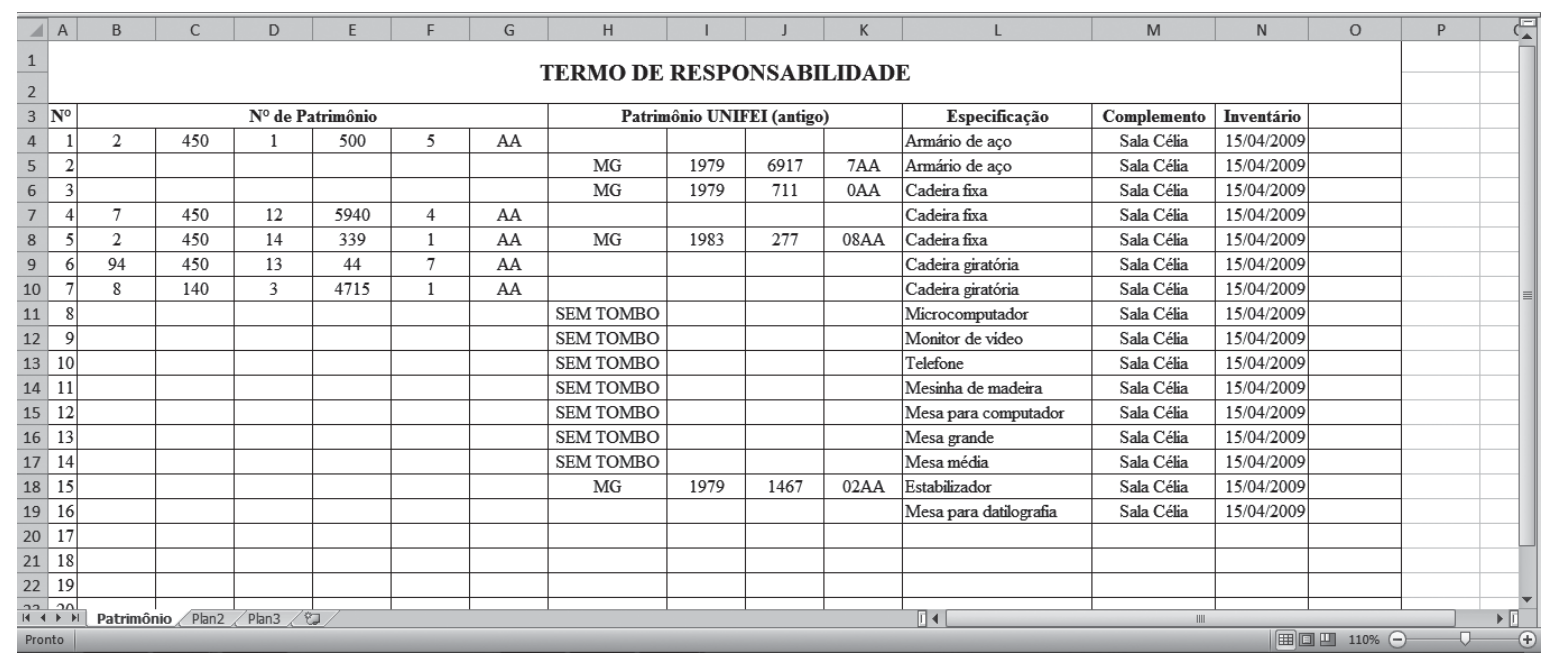


aspectos da produção de software, desde os estágios iniciais de especificação do sistema até sua manutenção depois que esse entrar em operação (SOMMERVILLE, 2007).

Para Filho (2011), o engenheiro de software é o profissional responsável por levantar, analisar e especificar o conjunto de requisitos, desenvolver o projeto, implementá-lo, testá-lo e entregar ao cliente. A Engenharia de software segue uma sequência de passos e utiliza ferramentas como CASE (Computer-Aided Software Engineering) que apóiam algumas atividades de processo. Para a construção do software de gerenciamento patrimonial foram seguidos os passos da metodologia RUP, que compõe a engenharia de software e suas ferramentas computacionais.

\subsubsection{Concepção}

A fase de concepção compreende o momento de discussões e análise das necessidades entre desenvolvedor e cliente. Para a coleta das informações necessárias ao desenvolvimento do software foram realizadas várias entrevistas com os funcionários do IEPG e futuros utilizadores do software, e foram elaborados formulários. O uso combinado de métodos qualitativos e quantitativos, conforme sugerem Pozzebon e Freitas (1997, p. 2), "permitiu maior sinergia na análise de dados".

Dentre as entrevistas feitas puderam-se perceber as necessidades e desejos do futuro software na visão do cliente. Essa concepção é muito importante, pois somente através do entendimento das informações transmitidas pelo cliente é possível a elaboração do escopo do projeto. Um resumo foi elaborado através de um questionário respondido por um entrevistado, mostrando suas principais necessidades.

\footnotetext{
"A principal necessidade que o Instituto tem hoje é a de concentrar informações sobre seus bens patrimoniais em uma única e confiável base de dados. Enfrentamos grandes problemas pela ausência dessa base. Nossas informações não são confiáveis, não podemos tomar decisões".

"Essa base de dados armazenaria informações como localização, número de tombamento e pessoa responsável pelos bens patrimoniais. Somente teriam acesso a essas informações, pessoas responsáveis pelo gerenciamento desse tipo de informação, em casos de auditoria ou verificação do estado do bem patrimonial". "Esse software teria um foco mais administrativo." (Relato do entrevistado).
}

O entrevistado nesse relato tentou transmitir ao desenvolvedor uma ideia básica das suas necessidades. Também expôs alguns problemas que enfrentam com a falta de uma ferramenta computacional para auxílio no desenvolvimento das atividades diárias com os bens patrimoniais. Demais entrevistas foram feitas com outros entrevistados, funcionários do IEPG e utilizadores do futuro software, para definir aspectos como telas, design, tamanhos, entre outras informações necessárias ao desenvolvedor. Foi elaborado ainda pelo desenvolvedor do software, e proposto às pessoas entrevistadas, um questionário para que pudesse ser preenchido com o objetivo de entender as necessidades e desejos dos usuários que irão fazer uso da ferramenta computacional.

Questionário proposto:

1. Que atividades deveriam ser executadas por um software de gerenciamento de patrimônio?

2. Quem são as pessoas responsáveis?

3. Qual(is) o(s) benefício(s) de uma solução bem-sucedida?

4. Como você caracterizaria um "bom" resultado (saída) gerado por uma solução bem-sucedida?

5. Que documentos você utiliza nas atividades: documentos, anotações, formulários, relatórios.

6. Você poderia me mostrar (ou descrever) o ambiente em que a solução será usada?

7. Que funções (lista de funções completa) devem ser executadas pelo sistema?

8. Quais informações devem ser fornecidas?

9. Quais informações serão produzidas?

10. Quais informações devem ser armazenadas?

11. Quais desempenhos são exigidos?

12. Existe tecnologia para desenvolver e operar o sistema?

13. Quais recursos especiais de desenvolvimento e produção serão exigidos?

As respostas do questionário contribuíram para o entendimento das necessidades dos usuários, que puderam através deste, expor seus desejos e pensamentos sobre o futuro software. Esses arquivos foram anexados junto à documentação necessária para o desenvolvedor e cliente, para posteriores consultas e análises.

\subsubsection{Elaboração}

Na fase de elaboração da metodologia RUP são definidos e elaborados o escopo do projeto e cronograma. Todas as informações e dados que foram coletados na fase de concepção serão agora utilizados para a definição da proposta de desenvolvimento. São definidas as ferramentas que serão utilizadas na construção do software, equipamentos para os futuros testes e o cronograma do desenvolvimento. A Figura 6 mostra o cronograma de desenvolvimento do software. 
Figura 6 - Cronograma de desenvolvimento do software

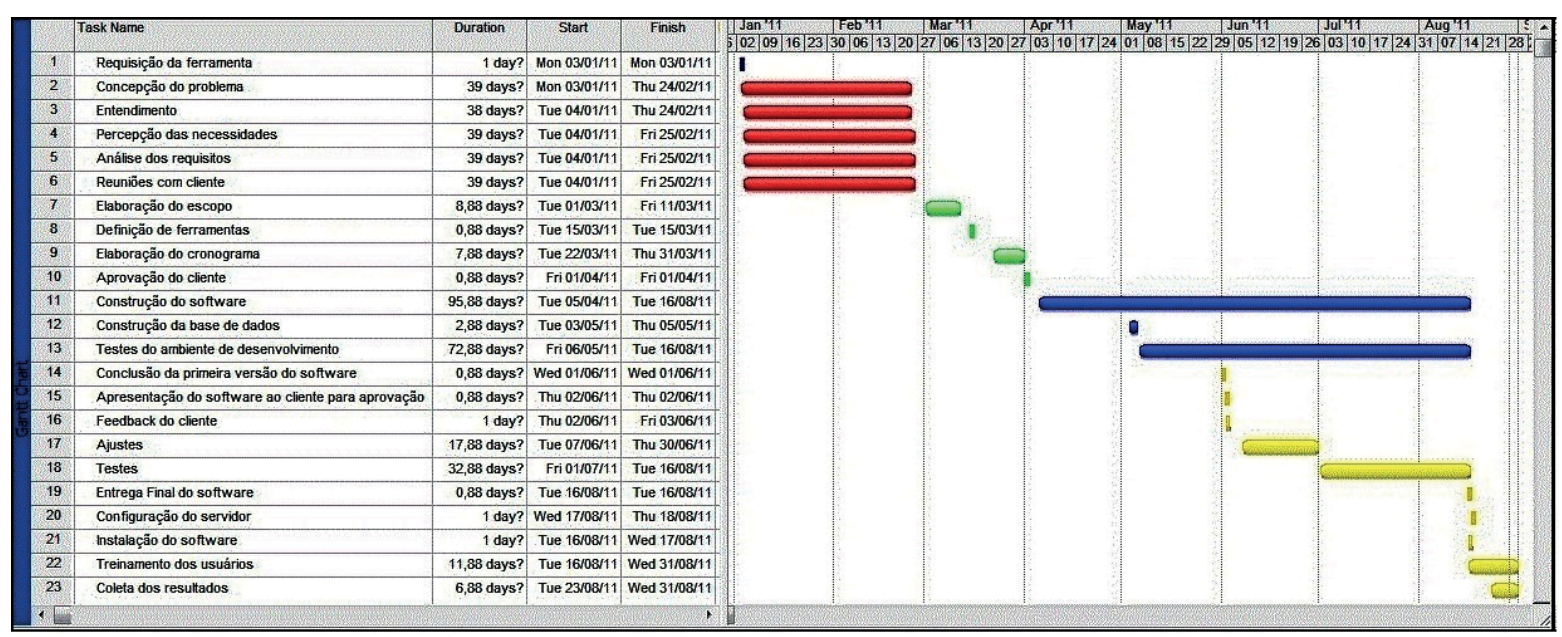

Fonte: Elaborado pelos autores

O cronograma de desenvolvimento é um documento importante para cliente e desenvolvedor no estabelecimento de metas e cumprimento das fases. É nele que são vistos os vencimentos dos prazos e a finalização de cada etapa do desenvolvimento, auxiliando principalmente o desenvolvedor na construção do software. A construção do cronograma foi feita utilizando o software Microsoft Office Projetc ${ }^{\circledR}$. A Figura 7 apresenta o escopo elaborado através das informações coletadas nas entrevistas e questionários com o cliente.

A ferramenta utilizada para a construção do escopo do projeto, mostrado na Figura 7, foi o software Astah Community $6.1{ }^{\circledR}$, uma ferramenta livre e de simples utilização. $\mathrm{O}$ Astah ${ }^{\circledR}$ é um software que modela vários tipos de diagramas, utilizado para desenhar fluxogramas e é útil para que seja possível a visualização de todos os processos que ocorrem em uma sequência de tarefas.

Para a construção de um software é necessária a utilização de um ambiente de programação, que é um IDE (Integrated Development Environment), isto é, uma plataforma de desenvolvimento integrado de programação. Nesse ambiente é desenvolvida toda programação do software, desde as linhas de códigos até a interface gráfica.

Para o desenvolvimento do software proposto foi o ambiente de desenvolvimento Netbeans IDE 7.0®, que é uma aplicação de código aberto, ou seja, também livre, feita pela empresa Oracle ${ }^{\circledR}$ e que tem objetivo de auxiliar os desenvolvedores na criação de aplicativos

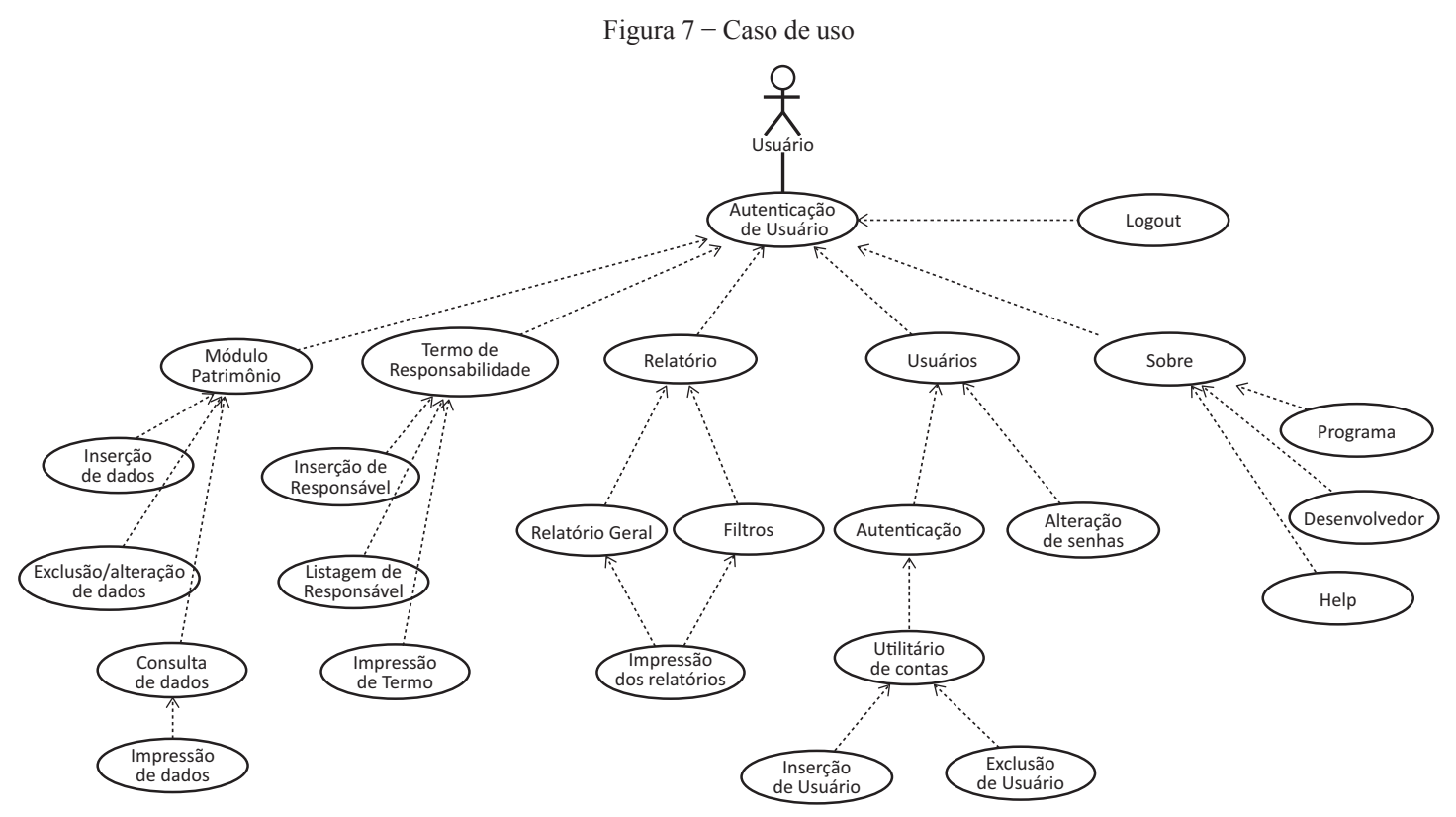

Fonte: Elaborado pelos autores 
em diferentes plataformas. Essa ferramenta é muito utilizada no ambiente de desenvolvimento de software nas grandes empresas, é uma plataforma que oferece todo o suporte para criação de interfaces gráficas de maneira visual, bem como o desenvolvimento de aplicações para a internet e celulares.

A linguagem de programação usada foi a Java. Java é uma linguagem de programação orientada a objetos, desenvolvida por uma pequena equipe de pessoas na Sun Microsystems ${ }^{\circledR}$. É uma linguagem de alto nível e simples, independente de arquitetura, robusta, segura, extensível, bem estruturada e distribuída. Além dessas vantagens, a linguagem Java permite o desenvolvimento de softwares e aplicações para web, desktop e celulares, sendo que pode ser executado em qualquer sistema operacional.

Ainda para o desenvolvimento do software é necessário um banco de dados. Banco de dados é o conjunto de arquivos, tabelas e relações que armazenam dados e as associações entre eles. Na construção do banco de dados foi utilizado o MySQL Server 5.5 ${ }^{\circledR}$, desenvolvido pela empresa Oracle ${ }^{\circledR}$. Um banco de dados é mantido e acessado por meio de um software conhecido como Sistema Gerenciador de Banco de Dados (SGBD).

O SGBD usado no desenvolvimento do software proposto foi o MySQL Workbench 5.2 CE®, também desenvolvido pela empresa Oracle ${ }^{\circledR}$, que é um sistema gerenciador de banco de dados que utiliza a linguagem $S Q L$ (Linguagem de Consulta Estruturada), como interface.
O SGBD é um software com interface que possibilita ao desenvolvedor a criação de banco de dados, tabelas e as relações existentes entre eles e onde serão armazenados os registros do software. A Figura 8 mostra simplificadamente a estrutura de um software ou aplicativo acessando os registros de uma base de dados, conforme Elmasri e Navathe (2006). Na Figura 8 apresentam-se as ferramentas utilizadas no desenvolvimento do software desenvolvido.

Na Figura 8 apresenta-se a sequência da utilização das ferramentas na visão do desenvolvedor. O software de gerenciamento de patrimônio é construído usando a plataforma Netbeans ${ }^{\circledR}$ e utiliza a linguagem de programação Java, acessando o banco de dados onde estão armazenados todos os registros dos bens patrimoniais do Instituto através do SGBD, e, assim exibe ao usuário a consulta feita pelo aplicativo desenvolvido. Todo o processo de desenvolvimento e criação do banco de dados somente é visto e compreendido pelo desenvolvedor. O usuário somente verá o aplicativo de gerenciamento de patrimônio e acessará os dados nele cadastrados, não ficando à sua vista as configurações avançadas.

\subsubsection{Construção}

Após a definição das ferramentas e equipamentos que seriam utilizados iniciou-se a construção do software e a realização de testes. A fase de construção coloca em prática o desenvolvimento do escopo e está essencialmente relacionada ao projeto, programação e testes do protótipo.

Figura 8 - Configuração de um sistema de banco de dados simplificado

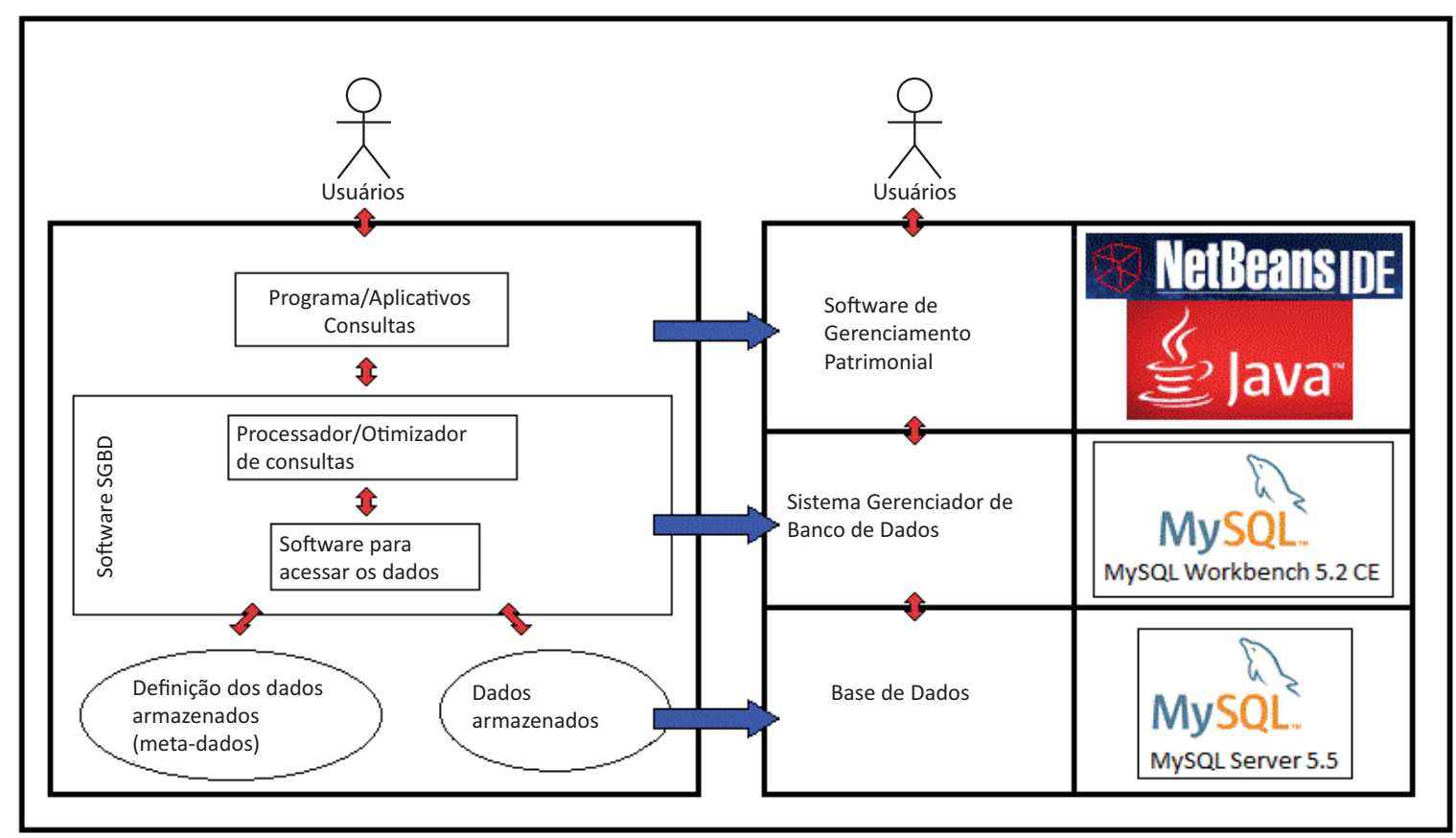




\subsubsection{Descrição do software}

O software possui uma interface amigável ao usuário, possibilitando dessa forma que o trabalho desenvolvido no software seja mais agradável e simples em sua utilização. A seguir é apresentada a tela inicial de apresentação do software de gerenciamento patrimonial desenvolvido (Figura 9).

Figura 9 - Tela de apresentação do software

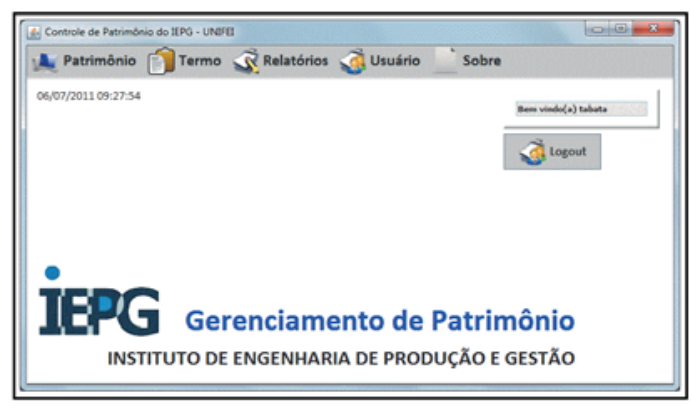

Fonte: Elaborado pelos autores

A tela de apresentação mostrada na Figura 9 é o corpo do software. Nessa tela serão desenvolvidas todas as tarefas e operações relacionadas aos bens patrimoniais. No menu "patrimônio", o usuário fará a inserção do material, com todas as informações necessárias como número de tombo, local de armazenamento, responsável por esse material e descrição. A descrição do material envolve informações importantes que são necessárias para diferenciar esse material dos demais e facilitar as consultas posteriores para esse bem.

Ainda nesse menu, o usuário terá uma tela de consulta com alguns campos que identificam o material, como a opção de procura através do "número de tombo", que o permite entrar com o número de patrimônio e o software irá consultar sua base de dados e retornará o material encontrado por esse número de tombo. Poderá também consultar pelo nome do "responsável" do material, ou pela "sala" onde está armazenado, ou ainda por um "código" que é gerado automaticamente pelo software a cada material inserido. O usuário pode também no menu "patrimônio", fazer a alteração dos campos de algum bem patrimonial ou a exclusão deste (Figura 10).

Figura 10 - Tela de Consulta

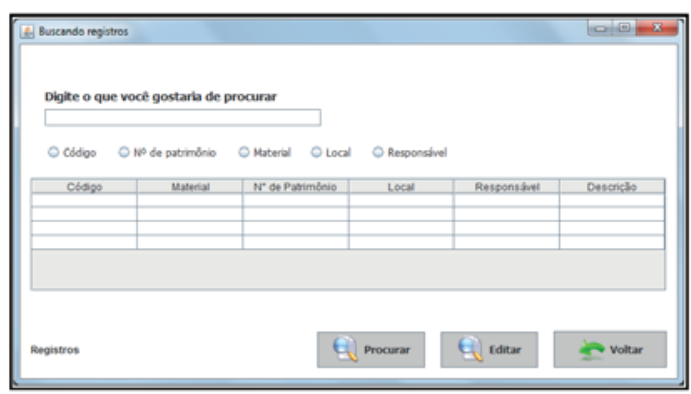

Fonte: Elaborado pelos autores
No menu "termo", o usuário irá cadastrar todos os responsáveis que o Instituto possui. Nesse cadastro será inserida, juntamente com o nome do responsável, a sala que está sob sua responsabilidade, sendo esse menu o responsável pela geração do Termo de Compromisso. O Termo de Compromisso é um documento que deverá ser impresso e encaminhado a cada responsável. Nele estarão descritos todos os critérios que devem ser seguidos, baseados na Instrução Normativa nº 205 (1988).

No menu "relatórios" o objetivo principal é a geração de diversos tipos de relatórios. Esse menu possui filtros, onde é possível a seleção dos itens desejados para a geração e impressão dos relatórios. A elaboração de relatórios permite fornecer informações em tempo real e atualizá-las para resolver problemas de localização e ajudar na tomada de decisões, como mostrado na Figura 11.

Figura 11 - Tela de Relatórios

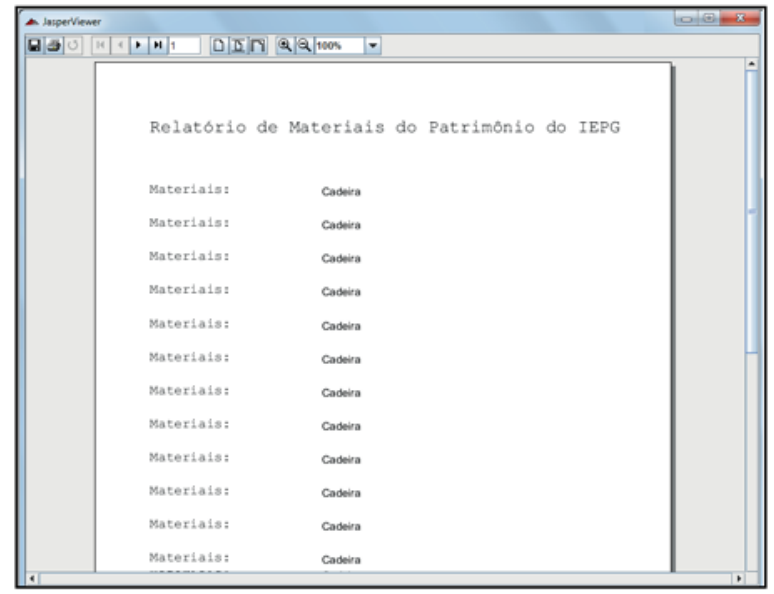

Fonte: Elaborado pelos autores

O menu "usuário" é utilizado pelo administrador do software para fazer a inserção dos usuários que irão utilizar o sistema, conforme a Figura 12. É definido um nome de login e uma senha para que cada usuário tenha acesso ao software. Após esse cadastro, os usuários que desejarem fazer a alteração da senha terão autorização. O menu "usuário" tem como objetivo garantir aos usuários a segurança de acesso, onde somente as pessoas que possuírem login e senha poderão fazer uso do software.

Figura 12 - Tela de Utilitários

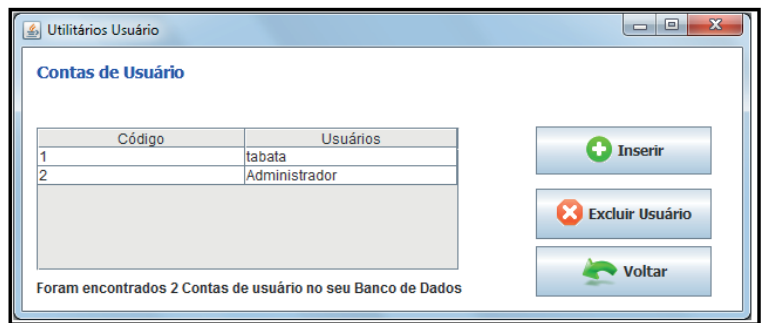

Fonte: Elaborado pelos autores 
No menu "sobre" é possível obter informações do software, como desenvolvedor e versão. Esse menu ainda possui um help, desenvolvido para auxiliar os usuários no funcionamento do software. A tela de apresentação do software possui um botão para logout, que o usuário deverá utilizá-lo quando necessitar sair do sistema (Figura 13).

Figura 13 - Tela de Login e Logout

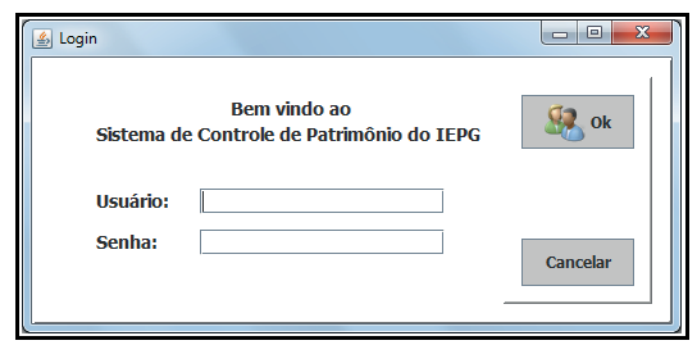

Fonte: Elaborado pelos autores

\subsubsection{Criação do banco de dados}

Com o uso do banco de dados MySQL Server $5.1{ }^{\circledR}$ e do SGBD MySQL Workbench 5.2 CE® foi construída a base de dados e foram armazenados todos os registros do Instituto que estavam atualizados e guardados em planilhas. Essa base de dados necessita ser gerenciada por um administrador, que deve realizar as configurações de backup. O backup das informações contidas no banco de dados é uma etapa importante dessa configuração, pois o backup garantirá uma cópia das informações do Instituto em caso de perda ou quaisquer outras fatalidades. As Figuras 14 e 15 apresentam os modelos lógico e relacional do banco de dados do software.

Figura 14 - Esquema Conceitua

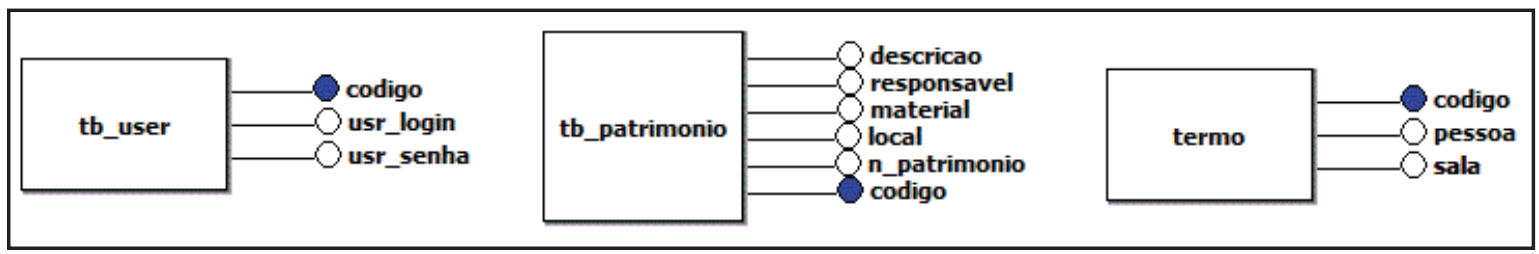

Fonte: Elaborado pelos autores

Figura 15 - Esquema Lógico

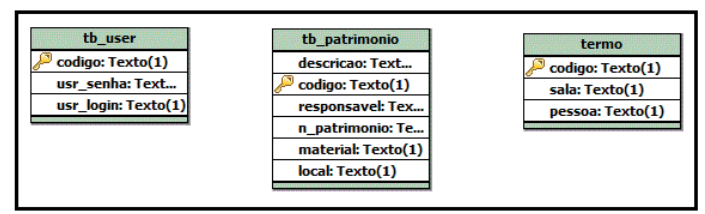

Fonte: Elaborado pelos autores

A base de dados construída para suportar as informações do Instituto foi instalada e configurada num servidor que está hospedado num local físico seguro, tendo acesso somente pessoas autorizadas. Um servidor tem como função hospedar algum tipo de aplicação que será utilizada por vários usuários, simultaneamente. Sendo assim, um mesmo servidor pode hospedar várias aplicações, desde que uma aplicação não interfira na outra.

\subsubsection{Transição}

A transição compreende a fase final do desenvolvimento do projeto, momento em que o software deixa de ser testado em laboratório e passa a fazer parte do dia-a-dia dos usuários no Instituto. Os primeiros testes eram feitos pelo próprio desenvolvedor e no ambiente em que foi desenvolvido. Após a conclusão do desenvolvimento da primeira versão do software, esta foi levada ao ambiente de trabalho do usuário para que pudessem fazer vários testes. Os usuários utilizaram o software para que, se houvesse a necessidade de correções, estas seriam feitas ainda nessa fase.

\subsection{Implantação do software e testes}

Com a criação e configuração do banco de dados no servidor, o protótipo do software foi instalado nas estações de trabalhos dos usuários. Foi feita uma apresentação do software com suas funções para que os usuários pudessem testar suas funcionalidades e dessem um feedback ao desenvolvedor. O protótipo ficou em uso nas estações de trabalho por aproximadamente três semanas e, diariamente, eram coletadas opiniões, sugestões, críticas e novas ideias dos usuários que eram levadas ao desenvolvedor, que continuava a construção da próxima versão.

Testes foram realizados no software pelos usuários. À medida que eram colhidos seus resultados, a implementação do software prosseguia. Os testes foram importantes na fase de transição, pois se pôde confirmar se o que foi requisitado pelo cliente estava sendo construído pelo desenvolvedor. Ao final dessa etapa foi requerido ao 
responsável uma listagem dos usuários que iriam fazer uso do software, devido ao número limitado de usuários que poderiam acessá-lo, para que, dessa forma, fosse possível realizar a instalação em seus locais de trabalho.

\subsection{Treinamento}

O treinamento foi realizado com os usuários em seu próprio ambiente de trabalho e, devido ao número limitado de usuários que teriam acesso ao software, o treinamento foi individual. Primeiramente foi inserido na base de dados do software o login e senha que o usuário irá utilizar para acessar o software. E, posteriormente, foram apresentadas todas as telas e janelas com suas respectivas funções. O treinamento dos usuários é importante, pois somente através dele o usuário poderá fazer uso adequado da ferramenta. Com a apresentação das telas e suas funcionalidades, foram retiradas dúvidas e questionamentos dos objetivos e limitações do software.

\subsection{Problemas enfrentados durante o desenvolvimento do software}

O principal problema enfrentado durante o desenvolvimento do software foi a falta de compartilhamento de informações entre os funcionários do IEPG. O procedimento adotado para a alimentação do banco de dados foi uma coleta manual de todos os bens do Instituto. Foram realizadas visitas pelo desenvolvedor a todas as repartições do IEPG. Os bens presentes em cada repartição foram catalogados com seus respectivos responsáveis. Verificou-se, com o passar do tempo, que alterações dos bens patrimoniais estavam ocorrendo entre as repartições do Instituto sem que essas fossem informadas à equipe de desenvolvimento do software, fato este que comprometeu o seu desenvolvimento. A alteração da localização dos bens, sem a devida informação pelos usuários, atrasou o andamento do cronograma, pois várias repartições tiveram que ser revisitadas para a correta atualização dos dados. Após essa nova coleta, pôde-se então alimentar, definitivamente, o banco de dados do software. A ferramenta desenvolvida para auxiliar os usuários do Instituto, como as demais ferramentas computacionais, infelizmente depende de ações humanas. Dessa forma, é necessário alterar as informações que o software possui quando essas mudanças forem feitas fisicamente no Instituto.

\section{Resultados da análise da aceitabilidade do software}

Os resultados alcançados com a análise de aceitabilidade do software foram notados no trabalho cotidiano dos usuários. Na execução de tarefas relacionadas aos bens patrimoniais do Instituto, a utilização do software proporcionou grande economia de tempo, possibilitando que os usuários tivessem em tempo real a informação da qual necessitavam em sua tela, evitando a procura em inúmeros arquivos que não garantiam integridade e não eram confiáveis. Para comprovar esses resultados foi aplicado um questionário de satisfação e usabilidade do software (SUMI - software usability measumerement inventory) a todos os funcionários do IEPG que o utilizaram. A Tabela 1 apresenta os resultados alcançados.

Tabela 1 - Questionário SUMI

\begin{tabular}{|l|c|c|c|}
\hline \multicolumn{1}{|c|}{ Perguntas } & Sim & Não sei & Não \\
\hline 1. O software é lento quanto à entrada de dados? & $0 \%$ & $0 \%$ & $100 \%$ \\
\hline $\begin{array}{l}\text { 2. Eu recomendaria esse software aos meus colegas } \\
\text { de trabalho de outros Institutos? }\end{array}$ & $100 \%$ & $0 \%$ & $0 \%$ \\
\hline 3. O software alguma vez parou de repente? & $0 \%$ & $0 \%$ & $100 \%$ \\
\hline 4. Aprender a usar esse software é difícil? & $0 \%$ & $0 \%$ & $100 \%$ \\
\hline 5. Nem sempre sei como concluir uma tarefa? & $20 \%$ & $0 \%$ & $80 \%$ \\
\hline 6. Eu gosto de interagir com o software? & $60 \%$ & $20 \%$ & $20 \%$ \\
\hline 7. A informação de ajuda é útil? & $80 \%$ & $0 \%$ & $20 \%$ \\
\hline 8. Nem sempre sei se estou fazendo a ação correta? & $20 \%$ & $0 \%$ & $80 \%$ \\
\hline 9. Trabalhar com esse software é satisfatório? & $80 \%$ & $20 \%$ & $0 \%$ \\
\hline 10. Há informações na tela quando necessário? & $80 \%$ & $0 \%$ & $20 \%$ \\
\hline 11. Eu acho que esse software é seguro? & $100 \%$ & $0 \%$ & $0 \%$ \\
\hline 12. A velocidade de resposta é rápida o suficiente? & $100 \%$ & $0 \%$ & $0 \%$ \\
\hline $\begin{array}{l}\text { 13. Está claro que as necessidades dos usuários } \\
\text { foram integralmente levadas em consideração. }\end{array}$ & $80 \%$ & $0 \%$ & $20 \%$ \\
\hline $\begin{array}{l}\text { 14. Esse software nem sempre fez o que eu } \\
\text { esperava? }\end{array}$ & $20 \%$ & $0 \%$ & $80 \%$ \\
\hline $\begin{array}{l}\text { 15. Tenho que buscar ajuda na maioria das vezes } \\
\text { quando uso esse software? }\end{array}$ & $0 \%$ & $0 \%$ & $100 \%$ \\
\hline 16. É fácil ver as relações entre as telas? & $100 \%$ & $0 \%$ & $0 \%$ \\
\hline
\end{tabular}

Fonte: Elaborado pelos autores

Da análise da Tabela 1, concluiu-se que o grau de aceitabilidade do software pelos usuários foi satisfatório, visto a elevada quantidade de respostas favoráveis a sua utilização. Pode-se ver na Tabela 1, Pergunta 11, que todos os usuários que responderam o questionário acreditam que o software desenvolvido é uma ferramenta computacional segura. Na pergunta dois, pode-se ver ainda que todos os usuários recomendariam o uso do software aos seus colegas de trabalho. Dessa maneira, conclui-se que a ferramenta computacional desenvolvida obteve um grau de aceitação e usabilidade elevado, e que o software desenvolvido será uma ferramenta amigável que irá auxiliar os usuários na realização de suas tarefas diárias.

Foi aplicada ainda uma pesquisa onde foram requisitados aos usuários que atribuíssem uma nota de 0 a 10 , sendo 0 uma nota ruim e 10 uma nota boa. Essa pesquisa abordou os seguintes pontos:

- Visibilidade;

- Affordance (Compreensão de ícones ou imagens); 
- Modelo conceitual (Efeito das ações);

- Mapeamentos (Relacionamento entre as interfaces);

- Feedback (Informações retornadas ao usuário).

Com as respostas dadas pelos usuários, chegou-se ao gráfico apresentado na Figura 16.

Figura 16 - Análise da aceitabilidade do software

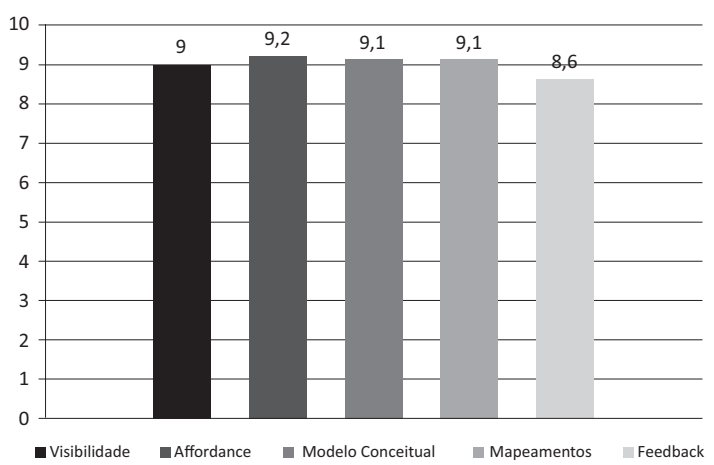

Fonte: Elaborado pelos autores

A Figura 16 apresenta a média feita através das respostas obtidas na pesquisa. Conclui-se que a análise apresentada demonstrou uma aceitabilidade por parte dos usuários de 90\%, percebendo-se, dessa maneira, que a interação dos usuários com o software foi satisfatória e possibilitará um bom trabalho no software. $\mathrm{O}$ software proporcionou a geração de diferentes tipos de relatórios, que serviu como embasamento para a tomada de decisões. Essas tomadas de decisões envolvem o remanejamento da distribuição dos materiais, noções de quantidade e tipo de equipamentos e necessidade de aquisição de compra de novos bens.

O software conseguiu, ainda, concentrar todas as informações do Instituto numa única base de dados e fazer com que os usuários utilizassem somente essa base de dados para realizar atualizações dos bens patrimoniais, eliminando dessa forma os dados inconsistentes das antigas planilhas. Sendo assim, foi possível resolver os problemas enfrentados pelo Instituto com a utilização do software.

\section{Conclusão}

Esse trabalho propõe uma ferramenta computacional para o gerenciamento de bens patrimoniais do Instituto de Engenharia de Produção e Gestão da UNIFEI. Com a implementação do projeto foi possível perceber que o uso adequado de um software pode trazer facilidade e agilidade em atividades comuns desenvolvidas pelos usuários.

Devido ao fato de o Instituto lidar com um grande volume de informações que não eram gerenciadas e organizadas, foi proposto o desenvolvimento do software de gerenciamento de patrimônio. Com o software desenvolvido, unificou-se toda a base de dados referentes aos bens patrimoniais do Instituto em uma única base, eliminando dessa forma a necessidade de outros arquivos que armazenem tais dados, inutilizando dezenas de planilhas que eram utilizadas antes da proposição do software. No entanto, com a constante mudança e compra de novos bens, faz-se necessário que o software seja bem gerenciado, atualizado e alimentado para que suas informações possam gerar bons resultados.

Após a conclusão do desenvolvimento do software, esse foi usado por usuários, nos quais perceberam que a ferramenta desenvolvida possibilitou agilidade em processos comuns, garantindo organização e integridade das informações, que são de grande importância para o Instituto. O projeto de desenvolvimento do software deu à direção do Instituto uma importante ferramenta de apoio à tomada de decisão. À medida que o número de bens patrimoniais do Instituto cresce, esses são organizados e gerenciados pelo software, sendo que essas informações estão disponíveis em qualquer situação. Por fim, o artigo proposto apresentou um problema enfrentado pelo IEPG que poderia ser resolvido de inúmeras maneiras. A solução apresentada contribui dessa forma para incrementar esse campo de pesquisa.

Cabe ressaltar que o trabalho aqui desenvolvido está sendo utilizado em um dos Institutos da UNIFEI, sendo um software local para controle interno. Dessa forma, um trabalho futuro poderia vir a desenvolver uma versão web que abrangesse toda a Universidade.

\section{Agradecimentos}

Os autores agradecem à Universidade Federal de Itajubá (UNIFEI), à Fundação de Ensino e Pesquisa de Itajubá (FEPI), à FAPEMIG e ao Programa de Pró-Engenharias da CAPES e CNPq pelo apoio e suporte ao longo dessa pesquisa.

\section{Referências}

ALBERTIN, L. A. Valor estratégico dos projetos de tecnologia de informação. Revista de Administração de Empresas, v. 41, n. 3, 2001.

BRASIL. Instrução Normativa $\mathrm{n}^{\circ} 205$, de 08 de abril de 1988. Objetiva a racionalização, com minimização de custos, do uso de material no âmbito do SISG. Disponível em: <www.ufpr.br/divisao_patrimonio/Instrucao_Normativa_205.doc $>$. Acesso em: 12 jul. 2011.

CRUZ, T. Sistemas de informações gerenciais: tecnologia da informação e a empresa do século XXI. 2. ed. rev. São Paulo: Atlas, 2000. 
ELMASRI, R.; NAVATHE, S. B. Sistemas de banco de dados. $1^{\text {a }}$ reimpressão. São Paulo: Pearson Addilson Wesley, 2006.

SILVA FILHO, A. M. Engenharia de Software Essencial para próximas décadas. Revista Espaço Acadêmico, p. 60-66, 2011.

LARMAN, C. Utilizando UML e padrões. 3. ed. Porto Alegre: Bookman, 2005.

LAUDON, K. C.; LAUDON, J. P. Sistemas de Informações Gerenciais: administrando a empresa digital. $1^{\mathrm{a}}$ reimpressão. São Paulo: Prentice Hall, 2004.

LAURINDO, F. J. B.; SHIMIZU, T.; CARVALHO, M. M.; RABECHINI, R. J. O papel da Tecnologia da Informação (TI) na estratégia das organizações. Gestão e Produção, v. 8, n. 2, p. 160-179, 2001.

MANUAL DE ADMINISTRAÇÃO PATRIMONIAL. Gestão financeira e de materiais - GEFIM. Universidade Estadual de São Paulo. 2010. Disponível em: < http:// www.usp.br/gefim/manuais/patrimonio.pdf $>$. Acesso em: 20 jun. 2011.

MARTINS, J. C. C. Gerenciando Projetos de desenvolvimento de Software com PMI, RUP e UML. 5. ed. Rio de Janeiro: Brasport, 2010.

MARTINS, P. G.; CAMPOS, P. R. Administração de materiais e recursos patrimoniais. 3. ed. São Paulo: Saraiva, 2009.

MAXIMIANO, A. C. A. Teoria Geral da administração: da revolução urbana à revolução digital. 6. ed. São Paulo: Atlas, 2009.

PACHECO, R. C. S.; TAIT, T. F. C. Tecnologia de Informação: evoluções e aplicações. Passo Fundo: UPF, 2000. Disponível em: <http://www.upf.br/cepeac/download/rev_n14_2000_art6.pdf>. Acesso em: 22 ago. 2011.

PADOVEZE, C. L. Contabilidade gerencial: um enfoque em Sistema de Informação Contábil. São Paulo: Atlas, 2000.
PISKE, O. R. RUP - Rational Unified Process. Mafra: UNC, 2003. Disponível em: <http://www.angusyoung. org/arquivos/artigos/trabalho_rup.pdf $>$. Acesso em: 10 ago. 2011.

POZZEBON, M.; FREITAS, H. Pela aplicabilidade com um maior rigor científico - dos estudos de caso em sistemas de informação. In: ENCONTRO NACIONAL DOS PROGRAMAS DE PÓS-GRADUAÇÃO EM ADMINISTRAÇÃO. Anais... Rio das Pedras: ANPAD, 1997.

REZENDE, D. A. Engenharia de Software e Sistemas de Informação. 3. ed. Rio de Janeiro: Brasport, 2005.

REZENDE, D. A.; ABREU, A. F. Tecnologia da informação aplicada a sistemas de informações empresariais. 3. ed. rev. São Paulo: Atlas, 2003.

SILVA, D. T.; GOMES, C. M.; SILVA, R. D. T. Impactos da utilização de um software de gestão integrada - ERP, na área contábil: um estudo de caso na USIMINAS. In: SIMPÓSIO DE EXCELÊNCIA EM GESTÃO E TECNOLOGIA. Anais... Resende, 2007.

SOMMERVILLE, I. Engenharia de Software. 8. ed. São Paulo: Pearson Addison-Wesley, 2007.

TEIXEIRA, E. A.; MENDONÇA, F. M.; SOUZA, F. L. As tecnologias de informação e os sistemas de gestão. In: V Congresso de Ciências Humanas, Letras e Artes. Anais... Ouro Preto, 2002.

TURBAN, E.; MCLEAN, E.; WETHERBE, J. Tecnologia da Informação para gestão. 3. ed. São Paulo: Bookman, 2002.

TURBAN, E.; RAINER, R. K.; POTTER, R. E. Administração de tecnologia da informação: teoria e prática. 3. ed. Rio de Janeiro: Elsevier, 2005.

Recebido em: 30/08/2011. Aceito em: 14/05/2013. 